\title{
Anticancer Activity of Marine Sponge Hyrtios sp. Extract in Human Colorectal Carcinoma RKO Cells with Different p53 Status
}

\author{
Hyun Kyung Lim, ${ }^{1}$ Woori Bae, ${ }^{1}$ Hyi-Seung Lee, ${ }^{2}$ and Joohee Jung ${ }^{1}$ \\ ${ }^{1}$ College of Pharmacy, Duksung Women's University, No. 33, 144-gil, Samyang-ro, Dobong-gu, Seoul 132-714, Republic of Korea \\ ${ }^{2}$ Korea Institute of Ocean Science \& Technology, 787 Haeanro, Ansan 426-744, Republic of Korea \\ Correspondence should be addressed to Joohee Jung; joohee@duksung.ac.kr
}

Received 20 June 2014; Revised 9 August 2014; Accepted 11 August 2014; Published 27 August 2014

Academic Editor: Shun-Fa Yang

Copyright ( $) 2014$ Hyun Kyung Lim et al. This is an open access article distributed under the Creative Commons Attribution License, which permits unrestricted use, distribution, and reproduction in any medium, provided the original work is properly cited.

\begin{abstract}
Drug development using marine bioresources is limited even though the ocean occupies about $70 \%$ of the earth and contains a large number of biological materials. From the screening test of the marine sponge extracts, we found Hyrtios sp. sponge collected from Chuuk island, Micronesia. In this study, the Hyrtios sp. extract was examined for anticancer activity against human colorectal carcinoma RKO cells that are wildtype for p53 and RKO-E6 that are p53 defective. The Hyrtios sp. extract dose-dependently inhibited viability in both cell lines. Multinucleation as an indication of mitotic catastrophe was also observed. Cytotoxicity tests gave significantly different results for RKO and RKO-E6 cells after $48 \mathrm{~h}$ exposure to Hyrtios sp. extract. In RKO cells treated with Hyrtios sp. extract, cell death occurred by induction of p53 and p21 proteins. In p53-defective RKO-E6 cells, Hyrtios sp. extract decreased expression of JNK protein and increased p21 protein. These results indicate that Hyrtios sp. extract induced apoptosis via different pathways depending on p53 status and could be a good natural product for developing new anticancer drugs.
\end{abstract}

\section{Introduction}

The ocean occupies about $70 \%$ of the earth and contains a huge number of marine organisms. Collection and identification of marine organisms were difficult for researchers and drug developers, but marine resources are still attractive for the application of pharmaceutical fields. Among marine resources, marine sponges are known to have about 15,000 species worldwide [1]. Marine sponges take in nutritious through body pores and produce secondary metabolites with bioactivity. In our ongoing research, we investigated the bioactivity of marine sponges before classifying and isolating their active compounds. Crude extracts were made from marine sponges collected from the Chuuk islands in Micronesia and investigated for anticancer effect. Screening tests identified some specimens with anticancer effects. One of the specimens was identified as Hyrtios sp. (Figure 1). Recently, Hyrtios sp. was reported to have cytotoxic $[2,3]$ and antioxidant activities [4]. Several Hyrtios metabolites
$[5,6]$ and active compounds $[2,4]$ have been reported, but the anticancer effects of Hyrtios sp. have not been reported. Herein, Hyrtios sp. extract was investigated for anticancer activity in human colorectal carcinoma RKO cells with different p53 status.

\section{Materials and Methods}

2.1. Specimen Preparation. Marin sponge specimens were collected by hand with scuba equipment at Chuuk state, Federated States of Micronesia, in October, 2010. Freshly collected specimens were washed by sterilized artificial sea water three times, immediately frozen, and stored at $-20^{\circ} \mathrm{C}$ until use. Lyophilized specimens were extracted with methanol $(3 \times 3 \mathrm{~L})$ as previous study [7]. All of the samples were provided from KIOST (Korea Institute of Ocean Science \& Technology). The extracts of specimens $(10 \mathrm{mg})$ were dissolved in sterile distilled water (the final concentration, 


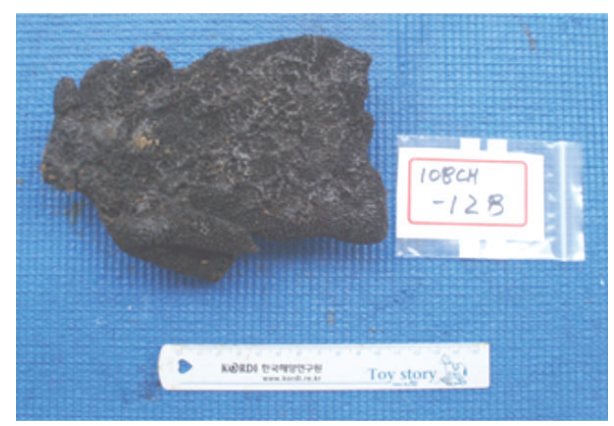

Figure 1: Morphology of Hyrtios sp. specimen before methanol extraction.

$50 \mathrm{mg} / \mathrm{mL}$ ). Aliquots of samples were stored at $-20^{\circ} \mathrm{C}$ until use.

2.2. Cells and Treatment. Human colorectal carcinoma RKO (CRL-2577) and RKO-E6 (CRL-2578) cells (ATCC, Manassas, VA) were cultured in Dulbecco's modified Eagle's medium (DMEM, GenDEPOT) supplemented with 10\% fetal bovine serum (GenDEPOT) and 1\% penicillin/streptomycin (GenDEPOT) in a humidified $5 \% \mathrm{CO}_{2}$ incubator. Cells used for the assays were in exponential growth phase. The samples were treated to the cell culture for $24 \mathrm{~h}$ or $48 \mathrm{~h}$.

2.3. Cell Cytotoxicity. Cell cytotoxicity was examined by Cell Counting Kit-8 (CCK-8, DOJINDO, Japan). Briefly, cells were seeded in 96-well plates at a density of $3 \times 10^{3}$ cells/well. After incubation for $24 \mathrm{~h}$, cells were treated with sponge samples for $24 \mathrm{~h}$ or $48 \mathrm{~h}$. CCK-8 reagent $(10 \mu \mathrm{L})$ was added to each well and incubated for $3 \mathrm{~h}$ at $37^{\circ} \mathrm{C}$. Absorbance at $450 \mathrm{~nm}$ was determined through microplate reader (Infinite M200 PRO, TECAN, Austria).

2.4. Cellular Morphology. Cells were seeded in 6-well plate at $4-6 \times 10^{4}$ cells/well and treated with Hyrtios sp. extract $(80 \mu \mathrm{g} / \mathrm{mL})$ for $48 \mathrm{~h}$. Cells were observed under light microscopy $(\times 40$ and $\times 400)$ (Nikon eclipse TS100, Japan).

2.5. Western Blot Analysis. Cells were seeded in 6-well plate at a density of $4 \sim 6 \times 10^{4}$ cells/well. Samples were treated to each well and incubated for $24 \mathrm{~h}$ or $48 \mathrm{~h}$. Cells were harvested and lysed in RIPA buffer (GenDEPOT) with protease inhibitors (Xpert protease inhibitor cocktail solution, GenDEPOT) and phosphatase inhibitors (Xpert phosphatase inhibitor cocktail solution, GenDEPOT). Cell lysates were boiled in $5 \times$ sample buffer and separated by $10 \%$ SDS-PAGE. Proteins were transferred onto PVDF membranes (Millipore) using a semidry electroblotter (Peqlab, Germany). Membranes were blocked with 5\% skim milk in TBST $(50 \mathrm{mM}$ Tris$\mathrm{HCl} \mathrm{pH} \mathrm{7.4,} 150 \mathrm{mM} \mathrm{NaCl}, 0.1 \%$ Tween 20) and incubated sequentially with primary antibodies at $4^{\circ} \mathrm{C}$, overnight. After washing membranes with TBST, the membranes reincubated with secondary antibody at room temperature for $3 \mathrm{hr}$. Immunoreactive protein was visualized using ECL reagents and developed with X-ray film. Antibodies and ratios at which they were used were p53, p21 (1:2000, Millipore), c-Jun N-terminal kinase (JNK, 1:500, Santa Cruz Biotechnology), $\beta$-actin (1:5000, Sigma-aldrich), and anti-mouse IgG $(\mathrm{H}+\mathrm{L})$ horseradish peroxidase conjugate and anti-rabbit IgG $(\mathrm{H}+\mathrm{L})$ horseradish peroxidase conjugate (1:3000, Bio-Rad).

2.6. Apoptosis. Cells were seeded in 6-well plate and treated as described for western blots. After incubation, cells were stained with Annexin V-FITC (Nexcelom Bioscience LLC) and propidium iodide (PI) solution. Apoptosis was detected using a Cellometer (Nexcelom Bioscience LLC).

\section{Results and Discussion}

3.1. Cytotoxicity of Hyrtios sp. Extract in RKO and RKO-E6. To evaluate cytotoxicity to cells with different p53 status, serially diluted samples of Hyrtios sp. extracts were treated to RKO and RKO-E6 cells for $24 \mathrm{~h}$ and $48 \mathrm{~h}$. As shown in Figure 2(a), cytotoxicity slightly increased in both RKO and RKO-E6 cells. Hyrtios sp. extract $(100 \mu \mathrm{g} / \mathrm{mL})$ inhibited $52.7 \pm$ $0.9 \%$ viability of RKO cells and $66 \pm 0.9 \%$ viability of RKO-E6 cells. Hyrtios sp. extract $(100 \mu \mathrm{g} / \mathrm{mL})$ for $48 \mathrm{~h}$ inhibited 26.5 $\pm 0.7 \%$ and $44.5 \pm 1 \%$ of cell viability in RKO and RKO-E6 cells, respectively (Figure 2(b)). Hyrtios sp. extract increased cytotoxicity time-dependently for RKO cells and RKO-E6 cells. The result showed that RKO cells were more sensitive than RKO-E6 cells to Hyrtios sp. extracts and indicated that the anticancer effects of Hyrtios sp. were different for RKO and RKO-E6 cells depending on their p53 status.

3.2. Hyrtios sp. Extract-Induced Mitotic Catastrophe. To investigate cell death induced by Hyrtios sp. extracts, cellular morphology was observed. RKO cells had fewer cells than RKO-E6 cells after treatment with Hyrtios sp. extracts (Figure 3(a)) consistent with cytotoxicity results. In particular, RKO cells treated with Hyrtios sp. extracts exhibited multinucleation and increased cell size, indications of mitotic catastrophe (Figure 3(b), upper right arrow). Hyrtios sp. might trigger the cell death induced by DNA damage.

3.3. Changes in p53, p21, and JNK Levels after Treatment with Hyrtios sp. Extract. To examine differences in cellular mechanisms between RKO and RKO-E6 cells, protein levels were determined by western blots. Expression of p53 protein was detected in RKO cells but not RKO-E6 cells (Figure 4). RKO cells treated with Hyrtios sp. extracts showed an increase of $\mathrm{p} 53$ protein levels and also increased expression of p21 protein which is encoded by a p53 target gene. In addition, p21 protein also increased in RKO-E6 cells treated with Hyrtios sp. extracts. JNK protein expression was slightly reduced in RKO and RKO-E6 cells (Figure 4). These results indicated that RKO cells exposed to Hyrtios sp. extracts induced cell death by increase of $\mathrm{p} 53$ protein, which activated the expression of $\mathrm{p} 21$ protein for $24 \mathrm{~h}$ (not shown) and 


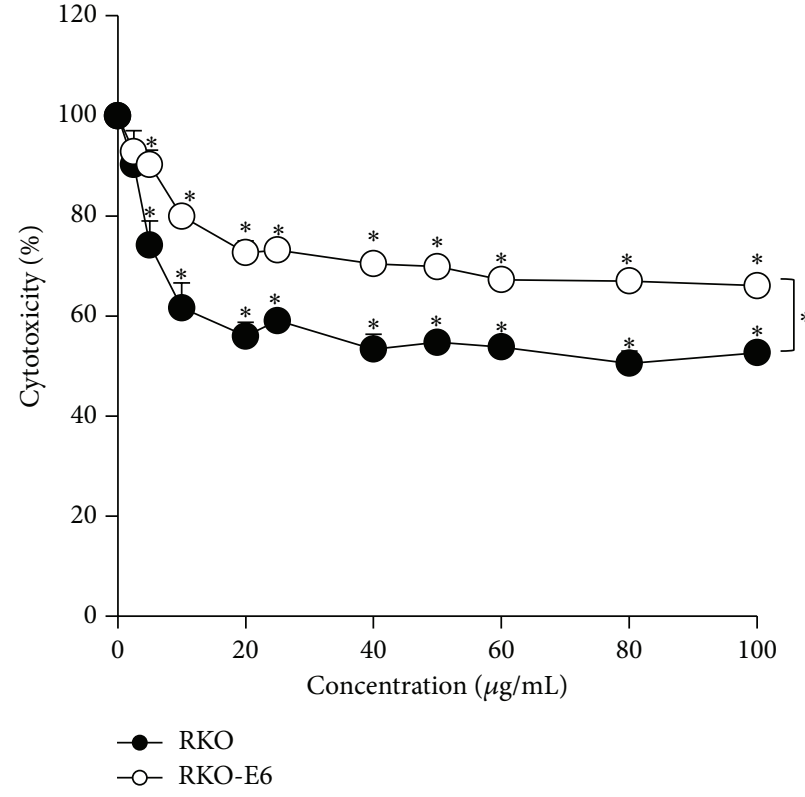

(a)

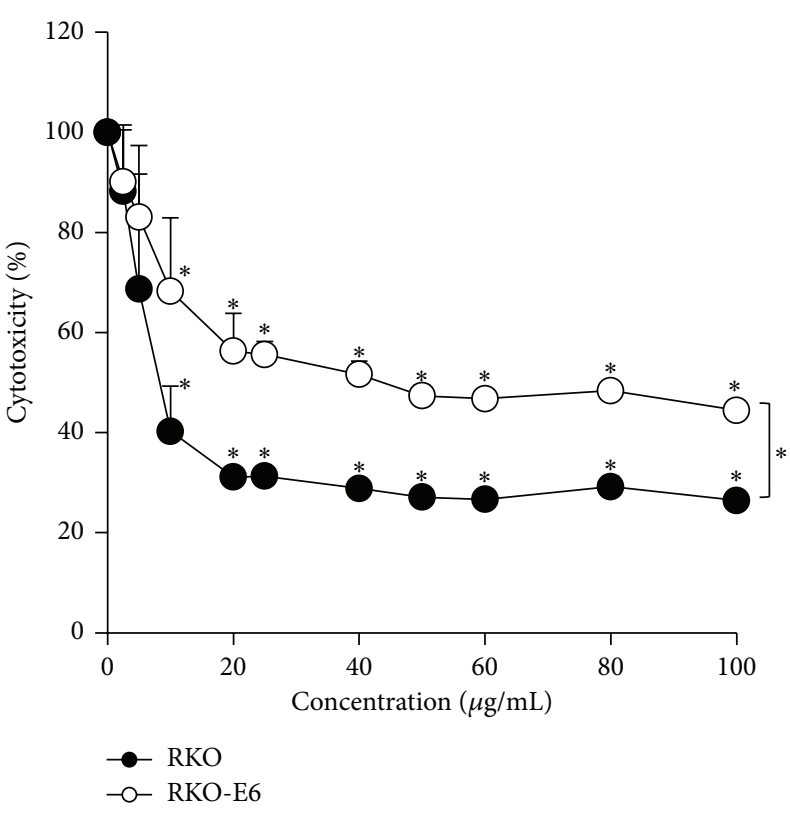

(b)

FIgURE 2: Inhibition of cell viability by Hyrtios sp. in RKO and RKO-E6 cells. Cells were treated with Hyrtios sp. extract and incubated for $24 \mathrm{~h}(\mathrm{a})$ and $48 \mathrm{~h}$ (b). Cytotoxicity was determined by CCK-8 assay. Data represent mean \pm standard deviations $(n=7), t$-test $\left({ }^{*} P<0.001\right)$.

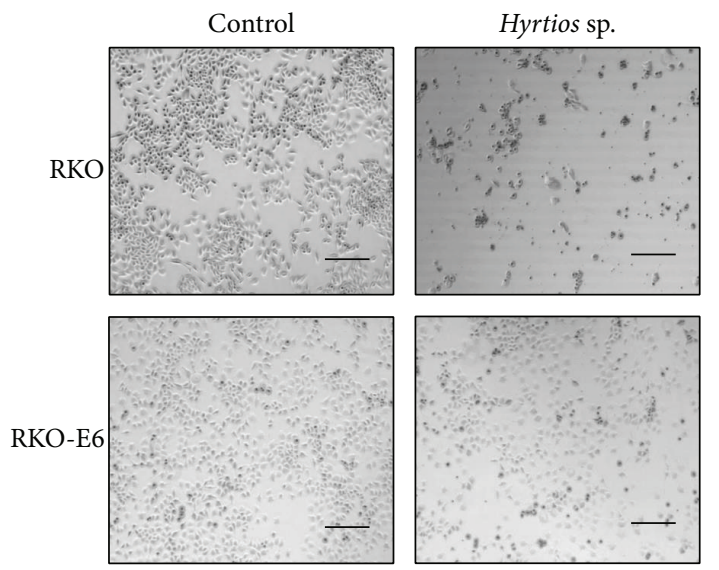

(a)
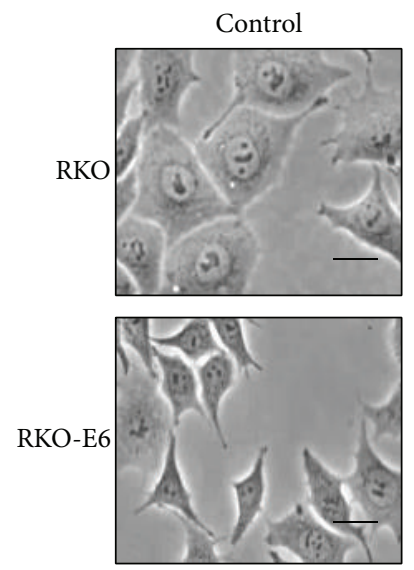

(b)

Figure 3: Change in cellular morphology after treatment with Hyrtios sp. extracts. Cells were treated with Hyrtios sp. extract (80 $\mu \mathrm{g} / \mathrm{mL})$ and incubated for $48 \mathrm{~h}$. (a) Scale bar $=500 \mu \mathrm{m}$. (b) Scale bar $=50 \mu \mathrm{m}$.

$48 \mathrm{~h}$, consistent with previous studies [8-10]. Surprisingly, RKO-E6 cells, which lack functional p53, showed slightly induced p53 protein expression after treatment with Hyrtios sp. extracts. However, RKO-E6 cells treated with Hyrtios sp. extracts inhibited cell growth through induction of p21 protein via a p53-independent pathway. These results suggested that suppression of JNK protein might be involved in p21 protein expression as previous study [11]. The JNK pathway is involved in phosphorylation of c-Jun [12] and p53 [13] and regulation of cell growth [14]. As reported by Potapova
[15], inhibition of JNK reduced the growth of p53-deficient cells and induced p21 protein expression. Our results were consistent with this study [15].

3.4. Induction of Apoptosis by Hyrtios sp. Extract. To verify cellular apoptosis, we used Annexin V and PI staining to investigate RKO and RKO-E6 cells treated with Hyrtios sp. extracts. As shown in Figure 5, apoptotic cells were detected similarly in RKO and RKO-E6 cells without treatment of 


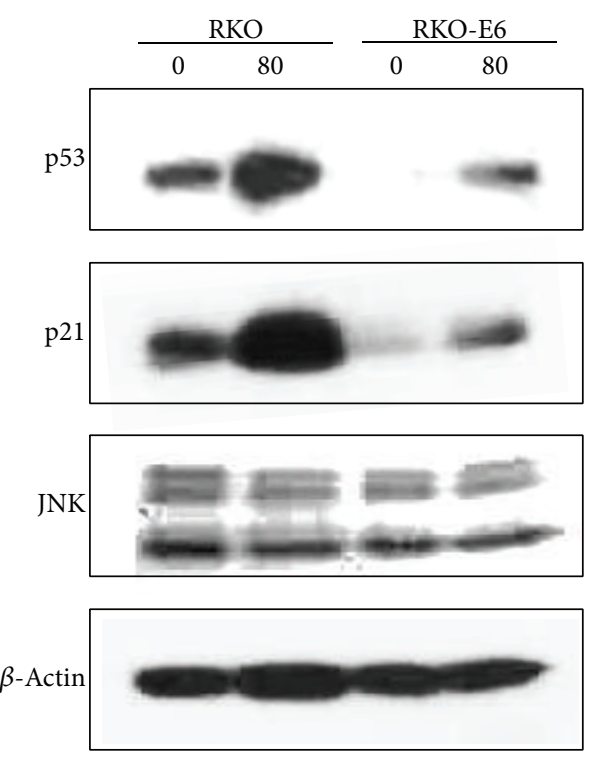

Figure 4: Expression of p53, p21, and JNK. Cells were treated with Hyrtios sp. extract $(80 \mu \mathrm{g} / \mathrm{mL})$ and incubated for 48 h. Protein expression was determined by western blots according to "Section 2 ".
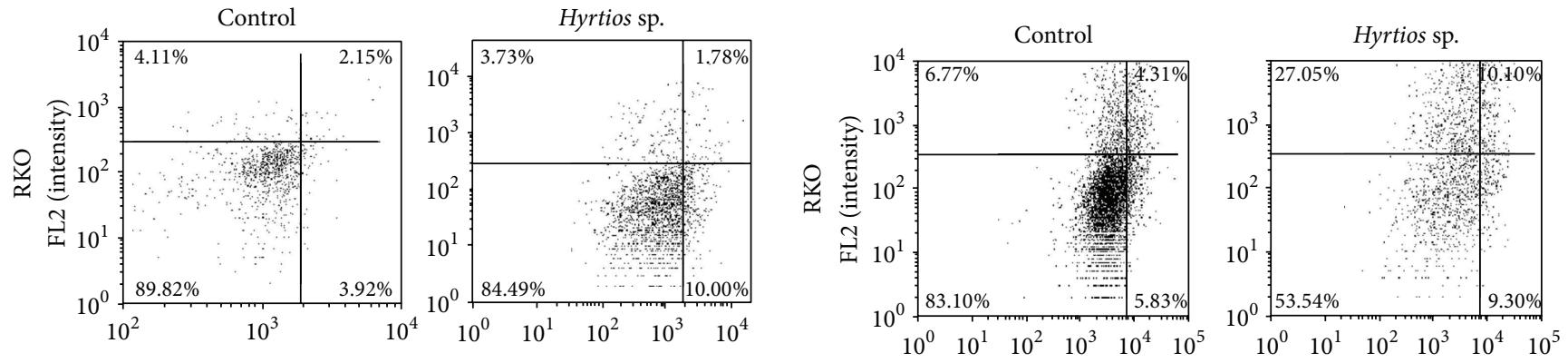

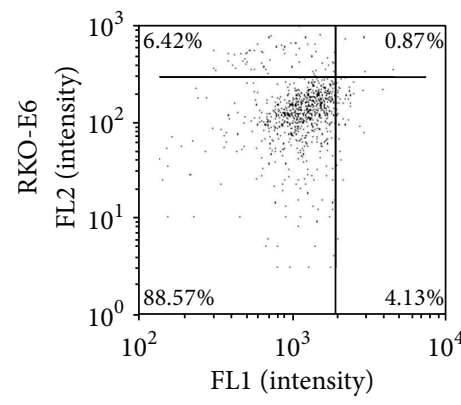

(a)

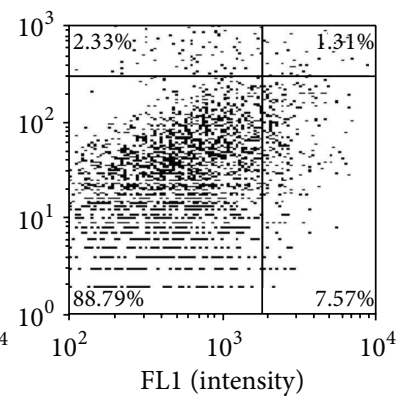

FL1 (intensity)
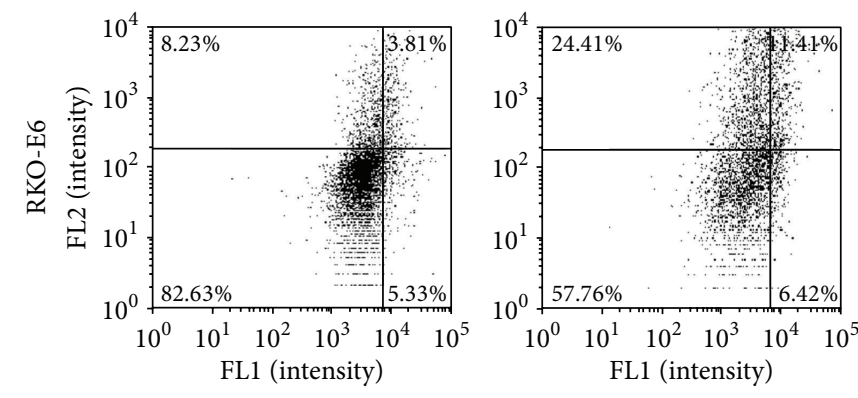

(b)

Figure 5: Hyrtios sp. extracts induced apoptosis. Cells were treated with Hyrtios sp. extract $(80 \mu \mathrm{g} / \mathrm{mL})$ and incubated for $24 \mathrm{~h}$ (a) or $48 \mathrm{~h}$ (b). Apoptotic cells were detected by Annexin V and PI staining.

Hyrtios sp. extracts. Hyrtios sp. extracts time-dependently decreased live cells and increased apoptotic cell death. RKO cells treated with Hyrtios sp. extract showed more apoptotic cells than RKO-E6 cells treated with Hyrtios sp. Extract. Therefore, Hyrtios sp. extracts induced more apoptosis in RKO cells than in RKO-E6 cells.

\section{Conclusions}

In this study, we investigated anticancer effects of Hyrtios sp. extract on p53 wild-type RKO cells and p53-deficient RKO-E6 cells. Our results indicated that Hyrtios sp. extract suppressed cell growth in both cell lines, but RKO cells, 
which have functional p53, were more sensitive to the cytotoxic effects of Hyrtios sp. extract than RKO-E6 cells. The anticancer effect of Hyrtios sp. extract was induced via activation of the $\mathrm{p} 53$ pathway in $\mathrm{RKO}$ cells and suppression of the JNK pathway in RKO-E6 cells. Hyrtios sp. is a natural marine sponge that could be a good candidate for cancer treatments. In a further study, the bioactive components of Hyrtios sp. will be investigated.

\section{Conflict of Interests}

The authors declare that there is no conflict of interests regarding the publication of this paper.

\section{Acknowledgment}

This study was supported by the Ministry of Oceans and Fisheries (PM57561), Korea.

\section{References}

[1] T. R. A. Thomas, D. P. Kavlekar, and P. A. LokaBharathi, "Marine drugs from sponge-microbe association-a review," Marine Drugs, vol. 8, no. 4, pp. 1417-1468, 2010.

[2] R. Momose, N. Tanaka, J. Fromont, and J. Kobayashi, "Hyrtimomines A-C, new heteroaromatic alkaloids from a sponge hyrtios sp.", Organic Letters, vol. 15, no. 8, pp. 2010-2013, 2013.

[3] T. Endo, M. Tsuda, J. Fromont, and J. Kobayashi, "Hyrtinadine A, a bis-indole alkaloid from a marine sponge," Journal of Natural Products, vol. 70, no. 3, pp. 423-424, 2007.

[4] A. Longeon, B. R. Copp, E. Quévrain et al., "Bioactive indole derivatives from the South Pacific marine sponges Rhopaloeides odorabile and Hyrtios sp.", Marine Drugs, vol. 9, no. 5, pp. 879888, 2011.

[5] N. Sata, M. A. Galario, N. Sitachitta, P. J. Scheuer, and M. Kelly, "Poipuol, a new metabolite from a Hawaiian sponge of the genus Hyrtios," Journal of Natural Products, vol. 68, no. 2, pp. 262-263, 2005.

[6] A. Mollica, M. Locatelli, A. Stefanucci, and F. Pinnen, "Synthesis and bioactivity of secondary metabolites from marine sponges containing dibrominated indolic systems," Molecules, vol. 17, no. 5, pp. 6083-6099, 2012.

[7] C. K. Kim, I. H. Song, H. Y. Park et al., "Suvanine sesterterpenes and deacyl irciniasulfonic acids from a tropical Coscinoderma sp. sponge," Journal of Natural Products, vol. 77, no. 6, pp. 13961403, 2014.

[8] W. S. El-Deiry, J. W. Harper, P. M. O'Connor et al., "WAF1/CIP1 is induced in p53-mediated G1 arrest and apoptosis," Cancer Research, vol. 54, no. 5, pp. 1169-1174, 1994.

[9] I. Bae, M. L. Smith, and A. J. Fornace Jr., "Induction of p53-, MDM2-, and WAF1/CIP1-like molecules in insect cells by DNAdamaging agents," Experimental Cell Research, vol. 217, no. 2, pp. 541-545, 1995.

[10] M. Barbareschi, O. Caffo, C. Doglioni et al., "p21WAF1 immunohistochemical expression in breast carcinoma: correlations with clinicopathological data, oestrogen receptor status, MIB1 expression, p53 gene and protein alterations and relapse-free survival," The British Journal of Cancer, vol. 74, no. 2, pp. 208215, 1996.
[11] H. Huang, Z. Liu, L. Ding et al., "Opposite effect of ERK1/2 and JNK on p53-independent p21 WAF1/CIP1 activation involved in the arsenic trioxide-induced human epidermoid carcinoma A431 cellular cytotoxicity," Journal of Biomedical Science, vol. 13, no. 1, pp. 113-125, 2006.

[12] J. M. Kyriakis, P. Banerjee, E. Nikolakaki et al., "The stressactivated protein kinase subfamily of c-jun kinases," Nature, vol. 369, no. 6476, pp. 156-160, 1994.

[13] M. C. Hu, W. R. Qiu, and Y. Wang, "JNK1, JNK2 and JNK3 are p53 N-terminal serine 34 kinases," Oncogene, vol. 15, no. 19, pp. 2277-2287, 1997.

[14] A. Minden, A. Lin, M. McMahon et al., "Differential activation of ERK and JNK mitogen-activated protein kinases by Raf-1 and MEKK," Science, vol. 266, no. 5191, pp. 1719-1723, 1994.

[15] O. Potapova, M. Gorospe, R. H. Dougherty, N. M. Dean, W. A. Gaarde, and N. J. Holbrook, "Inhibition of c-Jun N-terminal kinase 2 expression suppresses growth and induces apoptosis of human tumor cells in a p53-dependent manner," Molecular and Cellular Biology, vol. 20, no. 5, pp. 1713-1722, 2000. 

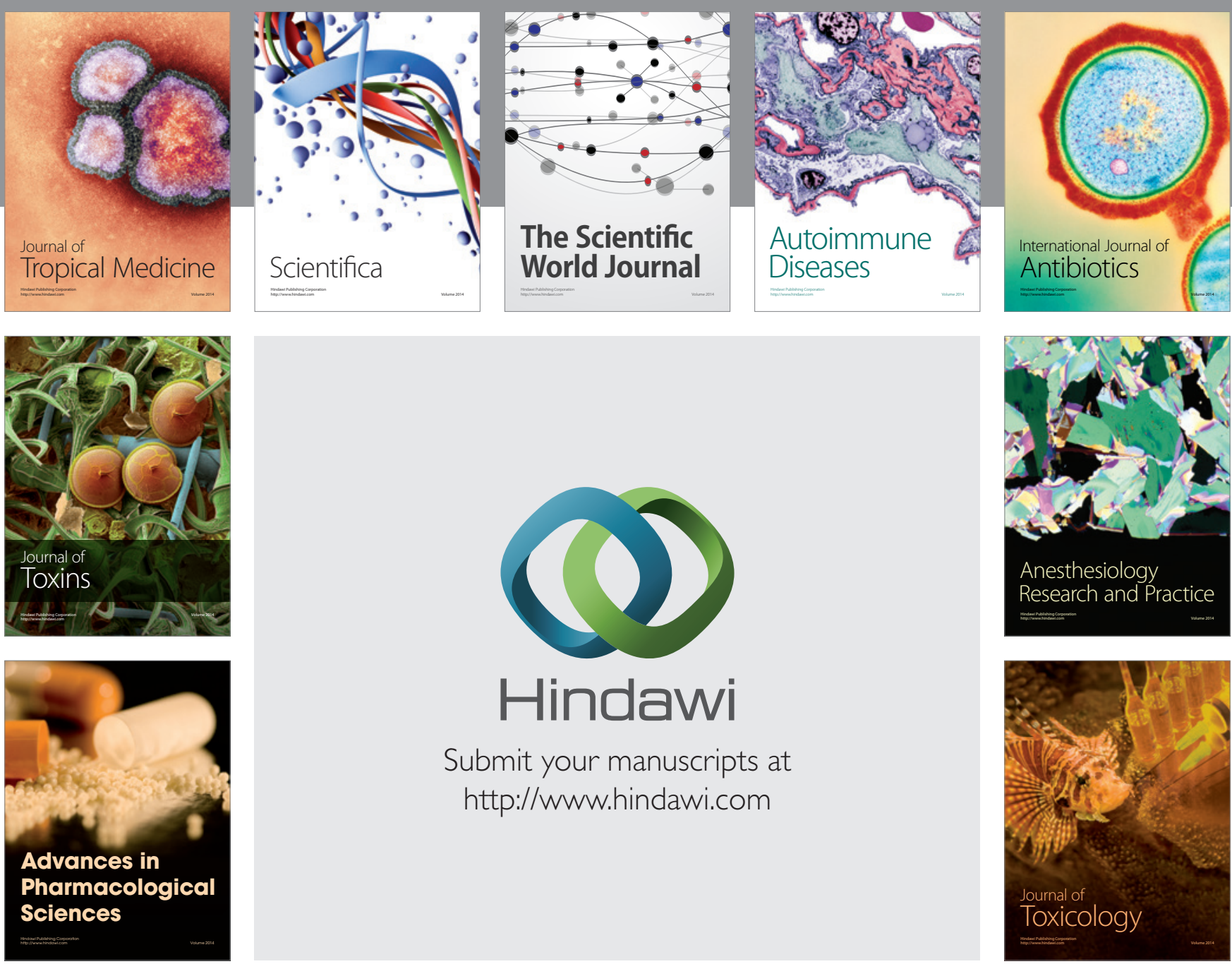

\section{Hindawi}

Submit your manuscripts at

http://www.hindawi.com
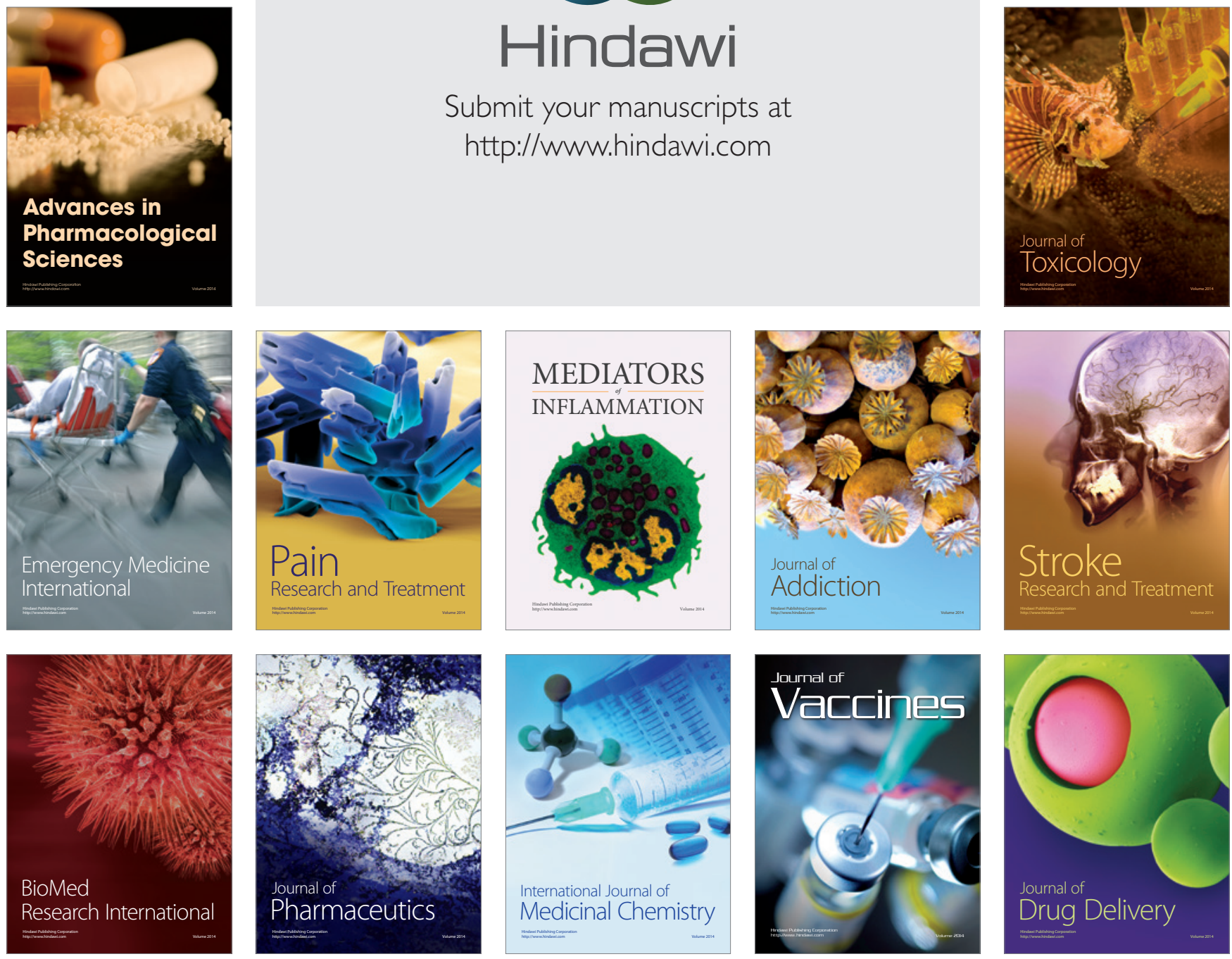